\title{
Combined Bidding Strategy of Multi-owner Cascaded Hydropower Stations in Day-Ahead Market
}

\author{
Ying Yang ${ }^{1}$, Weibin Huang ${ }^{1, *}$, Guangwen $\mathrm{Ma}^{1}$, Shijun $\mathrm{Chen}^{1,2,3}$, Gang $\mathrm{Liu}^{4}$, and Yue Liu ${ }^{1}$ \\ ${ }^{1}$ College of Water Resource and Hydropower, Sichuan University, Chengdu 610065, China \\ ${ }^{2}$ State Key Laboratory of Hydraulics and Mountain River Engineering, Sichuan University, Chengdu 610065, China \\ ${ }^{3}$ Business School, Sichuan University, Chengdu 610065, China \\ ${ }^{4}$ Sichuan Chuantou Energy CO.,LTD, Chengdu 610065, China
}

\begin{abstract}
Under the background of the electricity market reform, if the multi-owner cascade hydropower stations bid separately, the overall competitive advantages of river basin cannot be exerted, and the overall benefits cannot achieve the maximization. Based on the operation characteristics of cascade hydropower stations and the rule of competitive bidding, this paper established a bi-level optimal model for bidding game in day-ahead market, and used the Nash equilibrium principle of the game theory and genetic algorithm to solve this model, the optimal bidding strategies of the multi-owner cascade hydropower stations have been solved under the circumstances of bidding by oneself and alliance. The results from the calculating examples showed that the unified price declaration of the multi-owner cascade hydropower stations in day-ahead market can improve the overall and individual generation efficiency, and proved the effectiveness and feasibility of the combined bidding strategy in power market.
\end{abstract}

\section{Introduction}

With the implementation of a new round of power system reform, the operation of cascade hydropower stations in the basin will shift from a planned-oriented, market-assisted regulation mode to a comprehensive market-based competition. The concept of planned power generation in the power grid dispatching command mode will be more and more diminished, and more is to gain market share through the market value law ${ }^{[1]}$.

In the power competition market of "survival of the fittest", the bidding decision of the owner determines the competitive position of the power station in the market.

For multi-owner cascade hydropower stations, upstream and downstream power stations may belong to different owners. There is no direct communication channel between enterprises, management and decisionmaking are scattered, and their behaviors are diverse and uncertain. To obtain higher power generation benefits, the basin power generation companies, which are the main players in the market, have developed bidding strategies based on maximizing their own revenues.

The lack of coordination of runoff in each power station when participating in power generation competition may result in the lack of incentives for the upstream power station to comprehensively consider the total revenue of the cascade. The downstream power station faces information asymmetry risk and can only formulate its own operation plan by predicting the water storage and discharge law of the upstream power station.
This not only fails to give full play to the overall benefits of the basin, but also affects the optimal operation of cascade hydropower stations ${ }^{[2]}$.

Based on the combined bidding of the cascaded power stations and taking full account of the hydropower operation characteristics and scheduling constraints, we quantitatively analyze the changes in the revenue of each power station and formulate the optimal competition strategy for the cascade. Meanwhile, the optimized steplevel scheduling scheme will be beneficial to the economic operation of the cascaded power station groups, improve power generation efficiency, provide high-quality and reliable output, and maximize the overall benefits ${ }^{[3]}$.

Therefore, this paper takes the day-ahead market as an example to explore the relevant background conditions such as the cost function, combined quotation method and market trading system of the cascade hydropower station. Considering the constraints and linkages of hydropower between cascade hydropower stations, we have established a two-level target optimization bidding model based on the largest benefit of power producers and the lowest cost of electricity purchasers. In addition, based on the game equilibrium theory, the genetic algorithm is used to simulate the bidding behavior of the cascade hydropower stations, and the optimal strategy of the cascaded hydropower stations combined bidding is studied to provide reference for the cascade power stations to participate in the power market competition.

\footnotetext{
${ }^{*}$ Corresponding author:xhuang2002@163.com
} 


\section{Bidding game model in Day-Ahead Market}

\subsection{Hypothesis premise}

\subsubsection{Complete information}

In the market environment, each power station declares its own electricity price and electricity quantity to the power trading institution, and each does not know the other party's declaration data. However, this paper assumes that the power output parameters, variable costs, and incoming water information of each power station are known, so they can be regarded as a complete information game at the time of bidding.

\subsubsection{Linear cost function}

For a hydropower station that has been completed and put into operation, the annual depreciation, fixed materials fees, regular maintenance fees, employee compensation and benefits, and financial expenses will not change with the amount of electricity generated, which is a fixed cost; In the market environment, there is no fixed amount of power generation for power stations, and water fees and taxes are linearly related to power generation, which is a variable cost ${ }^{[4]}$. Therefore, the power generation cost function of the power station $\mathrm{i}$ can be expressed by a linear function related to the amount of power generation, i.e.

$$
C_{i}=a_{i} L_{i}+b_{i}
$$

Where, $C_{i}$ is the power generation cost of the power station $i ; a_{i}$ and $b_{i}$ are the variable cost coefficient and the fixed cost coefficient of the power station i, respectively, and $\mathrm{L}_{\mathrm{i}}$ is the power generation of the power station i.

\subsubsection{Combined bidding method}

To improve the bidding income, the power station can choose to form an alliance with the upstream and downstream power stations, formulate a bidding strategy, declare a unified electricity price, and coordinate their respective declared electricity levels ${ }^{[5]}$. This paper regards the cascade hydropower station of the alliance as an independent player and conducts a bidding game with the power station that has not joined the alliance. Meanwhile, this paper regards the other power stations outside the cascade hydropower stations as a whole, and considers them as "equivalent competitors", so as to better reflect the competition and cooperation relationship of the cascade hydropower stations in the market.

\subsubsection{Market trade system}

In this paper, day-ahead market of power trading is the bidding background, and the power trading institution announces the electricity demand information at 24 o'clock on the next trading day. Each power station will report to the trading institution the on-grid electricity price and electricity price at 24 o'clock on the next trading day in combination with its own power generation capacity. The trading institution sorts according to the electricity price declared by each power station from low to high. Under the constraints of the established market total demand at each time period, the dispatching organization arranges the power generation of the power stations according to the order until the system load demand is met. If the last few power stations that meet the load have the same declared price, but the total declared volume is greater than the demand gap, the remaining demanded electricity is allocated in proportion to the declared volume of each power station. The PAB (pay-as-bid) method is adopted for settlement, that is, settlement is performed according to the respective declared prices of each power station ${ }^{[6]}$.

\subsection{Model establishment}

In the actual bidding process, each power station maximizes its own revenue by making its own quotation, and the user decides the purchase of electricity for each power station according to the quotation of the power station to achieve the minimum purchase cost, so it is a two-level target optimization problem [7]. The upper level problem is the maximization of the revenue of the bidding game party, and the lower layer is the problem of minimizing the purchase cost of the user. The return value of each player in the upper layer problem is not only related to the quotation of the player, but also related to the result of the user's power distribution in the lower layer problem, and the optimal distribution result of the user to the purchased power is affected by the upper quotation.

A bidding cycle consists of several time periods. In the quotation, the cascade hydropower station should not only consider the capacity limitation of its own generator set, but also consider the water balance relationship between each time period and each power station ${ }^{[8]}$. Therefore, the quotes between the various periods are mutually influential. In this paper, a bidding period is divided into T time periods, each time period is $\Delta t$, then the bidding game model of each market entity participating in the day-ahead market is as follows.

(1) Upper objective function

The benefit of each power station can be expressed by its own electricity sales minus its cost. For Alliance $S$, which consists of multiple cascade power plants, the goal is to maximize the collective benefits, i.e.

$$
\max \pi_{s}=\sum_{i \in S} \sum_{t=1}^{T} \lambda_{i}(t) q_{i}(t) D_{s}(t)-C_{i}(t)
$$

where $\pi_{s}$ is the sum of the benefits of each power station in the alliance, $q_{i}(t)$ is the amount of electricity declared by the station i during the period $\mathrm{t}, D_{s}(t)$ is the unified electricity price declared by the members in the $t$ 
period, $\lambda_{i}(t) \in[0,1]$ is the proportion of the bid-wined electricity to the declared electricity, $C_{i}(t)$ is the power generation cost of the power station i during the $t$ period.

For a power station with a separate bid, the objective function is:

$$
\max \pi_{i}=\sum_{t=1}^{T} \lambda_{i}(t) q_{i}(t) D_{i}(t)-C_{i}(t) \quad i \notin S
$$

Where $\pi_{i}$ is the benefit of the power station $i$, and $D_{i}(t)$ is the electricity price declared by the power station i during the $t$ period.

(2) Upper constraints

For the cascade power station $\mathrm{i}(\mathrm{i}=1,2, \ldots, \mathrm{n})$, the following constraints are imposed within a bid period $\mathrm{t}(\mathrm{t}$ $=1,2, \ldots, \mathrm{T})$ :

(1) Electricity price constraint:

$$
D_{\min } \leq D_{i}(t) \leq D_{\max }
$$

Where $D_{\min }$ and $D_{\max }$ are the upper and lower limits of the electricity price specified in the power trading rules.

(2) Upstream and downstream water volume relationship and balance constraints:

$$
V_{i}(t)=V_{i}(t-1)+\left[R_{i}(t)-Q_{i}(t)-S_{i}(t)\right] \cdot \Delta t
$$

Where $V_{i}(t)$ and $V_{i}(t-1)$ are the storage capacity of the power station reservoir of the i power station at the end of the $t$ period and the end of the $\mathrm{t}-1$ period, $R_{i}(t)$ is the inflow flow of the i power station during the $t$ period, $Q_{i}(t)$ is the power generation flow of the i power station during the t period, $S_{i}(t)$ is the flow of abandoned water in the $t$ period of the i power station.

Considering the time delay of the upstream power station discharge flow, the inflow flow $R_{i}(t)$ can be expressed as follows:

$$
R_{i}(t)=I_{i}(t)+Q_{i-1}\left(t-\tau_{i-1}\right)+S_{i-1}\left(t-\tau_{i-1}\right)
$$

Where $I_{i}(t)$ is the interval flow of the i-power station during the $\mathrm{t}$ period, and $\tau_{i-1}$ is the number of time periods corresponding to the stagnation of the i-1 power station reservoir to the i power station reservoir.

(3) Reservoir water storage constraint

$$
V_{i, \min }(t) \leq V_{i}(t) \leq V_{i, \max }(t)
$$

$V_{i \text {,min }}$ is the minimum water storage capacity of the power station reservoir that should be guaranteed during the $\mathrm{t}$ period of the power station $\mathrm{i} ; V_{i, \max }$ is the maximum water storage capacity of the power station reservoir allowed by the power station $i$ during the $t$ period.

(4) Reservoir discharge flow constraint

$$
Q_{i, \text { min }}(t) \leq Q_{i}(t)+S_{i}(t) \leq Q_{i, \max }(t)
$$

$Q_{i, \min }$ is the minimum discharge flow that the power station i should guarantee, and $Q_{i, \max }$ is the maximum allowable discharge flow.

(5) Reservoir water level - storage relationship constraint

$$
Z_{i}^{u p}(t)=f_{1, i}\left[V_{i}(t)\right]
$$

$Z_{i}^{u p}(t)$ is the reservoir water level of the power station $\mathrm{i}$ at the $\mathrm{t}$ period, and $f_{1, i}()$ is the reservoir storage capacity curve of the power station $i$.

6) Tail water level - discharge flow constraint

$$
Z_{i}^{\text {down }}(t)=f_{2, i}\left[Q_{i}(t)+S_{i}(t)\right]
$$

$Z_{i}^{\text {down }}(t)$ is the tail water level of the power station $\mathrm{i}$ at the $\mathrm{t}$ period; Q $\mathrm{i}$ is the power generation flow; $f_{2, i}(\mathrm{)}$ is the relationship curve between the downstream tail water level and the flow rate of the power station $\mathrm{i}$.

(7) Output constraint:

$$
\begin{gathered}
P_{i}(t)=A_{i} Q_{i}(t) H_{i}(t) \\
P_{\min } \leq P_{i}(t) \leq P_{\max }
\end{gathered}
$$

Where $A_{i}$ is the comprehensive output coefficient of power station $\mathrm{I}, H_{i}$ is the average power generation net head, $P_{\min }=0, P_{\max }=E_{i}$, which is the maximum output.

(8) Cost function

$$
C_{i}(t)=a_{i} L_{i}(t)+b_{i}
$$

Where $C_{i}(t)$ is the power generation cost of the power station $i$ during the t period, $a_{i}, b_{i}$ are the variable cost coefficient and the fixed cost coefficient of the power station i, $L_{i}(t)$ is the bid-wined electricity of the power station i during the $t$ period, i.e. $L_{i}(t)=\lambda_{i}(t) q_{i}(t)$

(9) Non-negative constraints: The variables in the model are all non-negative values.

The output in the above constraints is based on the declared volume conversion.

(3) Lower objective function

According to the quotation of each power station, the user decides the power purchase plan that minimizes the purchase cost. The objective function is:

$$
\min \mu=\sum_{i \in S} \sum_{t=1}^{T} \lambda_{i}(t) q_{i}(t) D_{s}(t)+\sum_{i \notin S} \sum_{t=1}^{T} \lambda_{i}(t) q_{i}(t) D_{i}(t)
$$

Where $\mu$ is the user's purchase cost in a bidding cycle.

(4) Lower constraints

(1)Line blocking constraint:

$$
P_{i}(t) \leq P_{h}(t)-\sum_{j \neq i} P_{j}(t)
$$


Where $P_{i}(t)$ is the output of the power station $\mathrm{i}$ during the $\mathrm{t}$ period, which is obtained by the actual purchase of electricity, and $P_{h}(t)$ is the maximum transport capacity of the line during the $t$ period.

(2) Supply and demand balance constraint

$$
\sum \lambda_{i}(t) q_{i}(t)=L(t)
$$

(3) Purchase power constraint

$$
0 \leq \lambda_{i}(t) \leq 1
$$

\subsection{Model Solution}

The cascaded hydropower stations with separately bidding, the cascade power station alliances, and the power stations outside the cascade power stations, are regarded as independent bidding players, thus conducting a bidding game of 24 points in the market. Because the bidding game time dimension of the dayahead market has crossed over and the states of different time periods are mutually constrained, it is difficult to find its Nash equilibrium solution through mathematical analysis or constructing the income matrix. Therefore, this paper uses genetic algorithm to simulate the bidding game between power stations and find out the equilibrium solution of each game. The genetic algorithm encodes the solution of the problem into a string form by binary or real number, which is a "chromosome". Before solving with genetic algorithm, we first randomly generate a set of "chromosomes" as the initial solution of the problem, and then calculate the fitness of each "chromosome" according to the actual problem, so as to select individuals with higher fitness for replication. Secondly, we randomly select some "chromosomes" to cross and mutate to complete an evolution, resulting in a new generation of "chromosome" groups with higher fitness. After several generations of evolution, each individual of the population will eventually evolve into a "chromosome" with the highest fitness, which is the optimal solution to the problem ${ }^{[9]}$.

In order to facilitate the direct judgment of the constraint conditions, this paper uses the real number coding method in the genetic algorithm to encode the declared volume and price of each power station at 24 o'clock the next day. Assuming that the cascaded power stations have a total of $n$ levels, there are a total of $n+1$ bid volume stations in the market, and the resulting "chromosomes" are:

$$
\begin{aligned}
& X=\left(q_{1,1}, q_{1,2}, \ldots, q_{1,24}, D_{1,1}, D_{1,2}, \ldots, D_{1,24}, \ldots,\right. \\
& \left.q_{n+1,1}, q_{n+1,2}, \ldots, q_{n+1,24}, D_{n+1,1}, D_{n+1,2}, \ldots, D_{n+1,24}\right)
\end{aligned}
$$

For the i power station, given the quotation plan of other power stations, the optimal quotation strategy based on the above bidding model (solved by genetic algorithm) is encoded into the chromosome, we can get:

$$
\begin{aligned}
& X_{i}^{*}=\left(q_{1,1}, . ., q_{1,24}, D_{1,1}, . ., D_{1,24}, \ldots, q_{i, 1}^{*}, \ldots, q_{i, 24}^{*},\right. \\
& \left.D_{i, 1}^{*}, . ., D_{i, 24}^{*}, \ldots, q_{n+1,1}, \ldots, q_{n+1,24}, D_{n+1,1}, \ldots, D_{n+1,24}\right)
\end{aligned}
$$

According to the Nash equilibrium theory ${ }^{[10]}$, when the bidding game reaches equilibrium, the bidding strategy of each power station is based on the optimal decision result of other power station bidding strategies. The equilibrium solution of the game, that is, the "chromosome" code of the optimal solution of the genetic algorithm is:

$$
\begin{aligned}
& X^{*}=\left(q_{1,1}^{*}, . ., q_{1,24}^{*}, D_{1,1}^{*}, . ., D_{1,24}^{*}, \ldots, q_{i, 1}^{*}, \ldots, q_{i, 24}^{*},\right. \\
& \left.D_{i, 1}^{*}, . ., D_{i, 24}^{*}, \ldots, q_{n+1,1}^{*}, \ldots, q_{n+1,24}^{*}, D_{n+1,1}^{*}, \ldots, D_{n+1,24}^{*}\right)
\end{aligned}
$$

It can be seen that when $X_{i}^{*}=X_{j}^{*}=X^{*}(i \neq j)$, the bidding game reaches equilibrium. Therefore, when using genetic algorithms to solve game equilibrium, we can define the fitness function for evaluating "chromosomes" as:

$$
f=-\sum\left\|X_{i}^{*}-X_{j}^{*}\right\| \quad(i \neq j)
$$

Where $\left\|X_{i}^{*}-X_{j}^{*}\right\|$ is the Euclidean distance of two "chromosome" vectors.

\section{Application examples}

\subsection{Basic data}

In order to verify the effectiveness of the multi-owner cascade power station combined bidding strategy, this paper takes a 24-hour power bidding in day-ahead market as an example for analysis.

In addition to the cascade hydropower stations studied in this paper, the power producers in the market also include a number of hydropower, thermal power, new energy and other types of units. Substituting them into the bidding model not only increases the complexity of the calculation, but also has little effect on the choice of separate bidding or combined bidding strategies for the cascade hydropower stations. Therefore, this paper generalizes the bidding body of the day-ahead market into a group of multi-owner cascade power stations and independent power stations equivalent to other power stations in the system. Among them, cascade hydropower stations have a total of "one bank, three levels" and belong to different owners. From upstream to downstream, it is Power Station A, Power Station B and Power Station $\mathrm{C}$, and other bid volume stations are equivalent to independent power station $\mathrm{D}$. The total installed capacity of the system is $11780 \mathrm{MW}$.

The bidding period is 24 hours a day, and each hour is a quotation period. Each power station needs to declare the electricity price and electricity amount of each bidding period one day before the biding.

(1) System load curve. According to the situation that the power supply exceeds the demand, and the characteristics of the daily power load change, the system load curve in the bidding period is drawn up. As shown in Figure 1, the total power demand of the user during the day is $159517.8 \mathrm{MWh}$. 


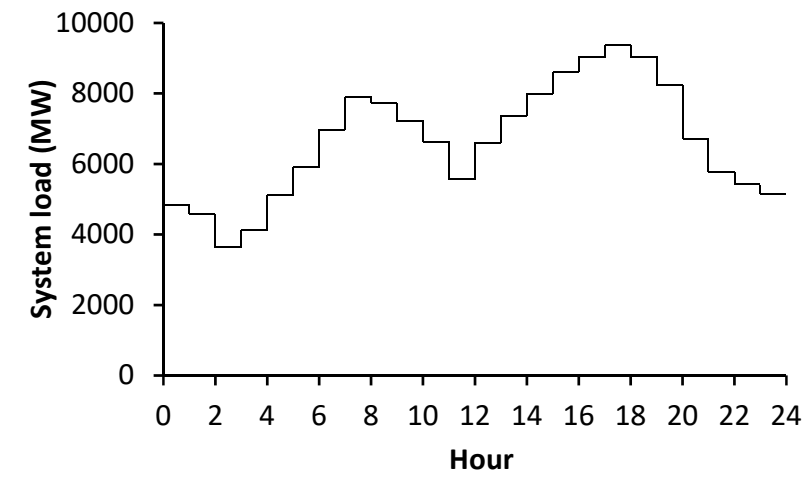

Fig. 1. System load curve

(2) Basic parameters of the bidding stations. The power generation parameters and cost of each power station in the bidding period under study are shown in Table 1.

(3) Watershed runoff data. In the bidding cycle, the predicted water supply of the first reservoir of cascade hydropower stations is shown in Figure 2.

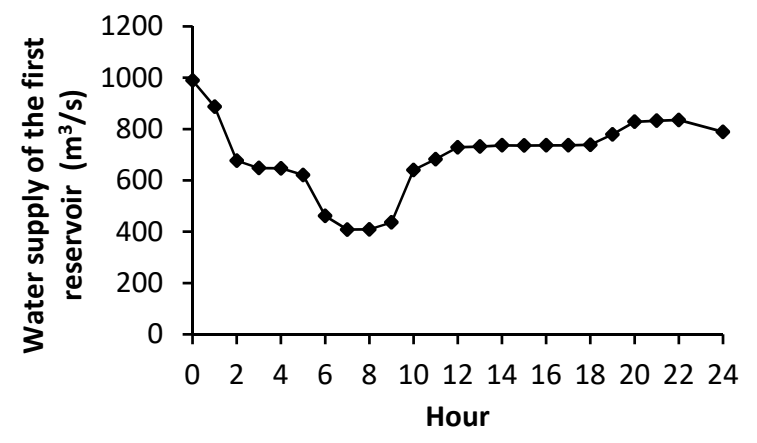

Fig. 2. Inflow prediction curve

\subsection{Analysis of bidding results}

The three cascade power stations and other power stations in the market obtain power generation rights through centralized bidding, and those with lower prices are preferred to generate electricity. The transaction price is based on the benchmark price of 288 yuan / $\mathrm{MWh}$ for the upper and lower 15\% floating limit price, so the highest price is 331.5 yuan / MWh, the lowest price is 244.8 yuan / MWh. Since the power station D is a virtual power station that is generalized for the remaining power stations of the system, the power generation constraint conditions between the time periods are not considered at the time of declaring the power. When the cascade power stations are bidding separately, the optimal quotation strategy of each power station obtained by genetic algorithm is shown in Table 2.

When the cascade power stations are combined bidding, each power station declares a unified electricity price, and the optimal quotation strategy is shown in Table 3.

According to the quotation of each power station, based on the market clearing rules, the following bidding results are obtained:

(1)When the cascade power station is bidding separately and in the alliance, the accumulated bid volume and proportion of electricity within the day are shown in Figure 3. Through the combined bidding, the overall bid of the ladder has increased by $10096 \mathrm{MWh}$, and the percentage of winning the bid has increased by $20 \%$. Due to the increase of on-grid electricity, the utilization rate of water resources in the basin has been improved.

(2) Combining the power generation costs of cascade hydropower stations, we get the benefits that each power station has achieved during the bidding cycle. As shown in Figure 4, the overall benefit of the cascade power station increased by 1.615 million yuan through the combined quotation, and the benefits of each power station have also been improved, which is conducive to the enthusiasm of the basin hydropower enterprises to carry out production and operation.

(3) In the case of the separate bidding and combined bidding of the cascade power station, the user's electricity purchase cost is 45.42 million yuan and 45.170 million yuan respectively, and the average purchase price is 284.78 yuan/MWh and 283.11 yuan/MWh. Therefore, for the user side, the cascade power station can suppress the market-powered power producers to raise the quotation through the alliance quotation, reduce its control over the market price, thereby reducing the electricity price level and reducing the user's electricity purchase cost.

Table 1. Basic parameters of the bidding stations

\begin{tabular}{ccccccc}
\hline Station name & $\begin{array}{c}\text { Normal water } \\
\text { level }(\mathrm{m})\end{array}$ & $\begin{array}{c}\text { Normal water } \\
\text { level }(\mathrm{m})\end{array}$ & $\begin{array}{c}\text { Efficiency } \\
\text { coefficient }\end{array}$ & $\begin{array}{c}\text { Maximum } \\
\text { generating } \\
\text { discharge } \\
\left(\mathrm{m}^{3} / \mathrm{s}\right)\end{array}$ & $\begin{array}{c}\text { Initial water } \\
\text { level (m) }\end{array}$ & $\begin{array}{c}\text { Installed } \\
\text { capacity (MW) }\end{array}$ \\
\hline A & 850 & 790 & 8.29 & 2772 & 792.00 & 3600 \\
cost(yuan / \\
B
\end{tabular}

Table 2. The optimal bidding strategies when bidding separately

\begin{tabular}{ccccccc}
\hline & \multicolumn{2}{c}{ Station A } & \multicolumn{2}{c}{ Station B } & \multicolumn{2}{c}{ Station C } \\
\cline { 2 - 6 } Hour & $\begin{array}{c}\text { Declared } \\
\text { volume(MWh) }\end{array}$ & $\begin{array}{c}\text { Declared } \\
\text { price(yuan/MWh) }\end{array}$ & $\begin{array}{c}\text { Declared } \\
\text { volume(MWh) }\end{array}$ & $\begin{array}{c}\text { Declared } \\
\text { price(yuan/MWh) }\end{array}$ & $\begin{array}{c}\text { Declared } \\
\text { volume(MWh) }\end{array}$ & $\begin{array}{c}\text { Declared } \\
\text { price(yuan/MWh) }\end{array}$ \\
\hline 1 & 2093.47 & 318.6 & 455.97 & 310.5 & 212.38 & 259.2
\end{tabular}




\begin{tabular}{ccccccc}
2 & 2071.06 & 255.1 & 259.39 & 299.2 & 5.91 & 249.1 \\
3 & 2342.81 & 267.0 & 222.65 & 254.2 & 242.07 & 289.8 \\
4 & 2002.57 & 299.0 & 660.00 & 270.0 & 274.31 & 280.7 \\
5 & 260.65 & 258.1 & 603.03 & 273.2 & 138.51 & 321.3 \\
6 & 1735.11 & 304.8 & 539.13 & 261.4 & 250.50 & 314.4 \\
7 & 2332.67 & 291.5 & 632.81 & 259.1 & 276.86 & 307.7 \\
8 & 2404.57 & 274.2 & 48.41 & 294.0 & 371.10 & 269.2 \\
9 & 2472.95 & 325.7 & 601.07 & 303.4 & 318.22 & 308.6 \\
10 & 921.83 & 292.5 & 660.00 & 313.7 & 426.15 & 248.1 \\
11 & 2097.85 & 321.8 & 660.00 & 288.4 & 364.12 & 299.9 \\
12 & 1788.83 & 306.9 & 434.96 & 298.1 & 510.50 & 274.7 \\
13 & 1528.52 & 268.8 & 637.21 & 264.6 & 370.66 & 298.5 \\
14 & 1786.86 & 271.6 & 633.70 & 302.3 & 645.49 & 327.6 \\
15 & 2412.83 & 328.8 & 502.58 & 293.0 & 406.56 & 310.7 \\
16 & 1848.89 & 300.5 & 256.62 & 326.8 & 614.74 & 281.8 \\
17 & 2378.05 & 310.6 & 660.00 & 284.0 & 631.15 & 290.9 \\
18 & 1898.60 & 310.1 & 610.39 & 263.4 & 619.76 & 324.9 \\
19 & 452.94 & 299.4 & 642.30 & 272.0 & 653.42 & 281.4 \\
20 & 1881.23 & 269.6 & 444.48 & 248.6 & 488.22 & 294.3 \\
21 & 2240.54 & 314.5 & 197.53 & 307.0 & 586.11 & 298.9 \\
22 & 836.20 & 293.2 & 495.94 & 292.3 & 360.42 & 326.9 \\
23 & 839.29 & 323.6 & 660.00 & 320.5 & 653.33 & 330.8 \\
24 & 621.19 & 286.5 & 466.08 & 250.0 & 567.95 & 310.1 \\
\hline
\end{tabular}

Table 3. The optimal bidding strategies when bidding in the alliance

\begin{tabular}{|c|c|c|c|c|}
\hline \multirow{2}{*}{ Hour } & \multicolumn{3}{|c|}{ Declared volume(MWh) } & \multirow{2}{*}{$\begin{array}{c}\text { Declared } \\
\text { price(yuan/MWh) }\end{array}$} \\
\hline & Station A & Station B & Station C & \\
\hline 1 & 340.98 & 224.17 & 93.84 & 323.8 \\
\hline 2 & 1519.83 & 277.58 & 63.06 & 325.5 \\
\hline 3 & 1742.43 & 92.33 & 61.32 & 266.4 \\
\hline 4 & 932.52 & 516.82 & 382.21 & 303.0 \\
\hline 5 & 1025.86 & 590.83 & 205.21 & 262.9 \\
\hline 6 & 2203.57 & 465.26 & 13.15 & 318.0 \\
\hline 7 & 2149.24 & 158.35 & 237.35 & 279.8 \\
\hline 8 & 1819.87 & 656.35 & 368.87 & 278.3 \\
\hline 9 & 1749.33 & 144.13 & 473.69 & 284.4 \\
\hline 10 & 1471.43 & 534.34 & 290.01 & 260.8 \\
\hline 11 & 1012.13 & 636.51 & 583.34 & 327.2 \\
\hline 12 & 2137.36 & 305.16 & 105.62 & 293.7 \\
\hline 13 & 2198.19 & 386.52 & 115.74 & 246.8 \\
\hline 14 & 747.57 & 598.64 & 314.48 & 286.7 \\
\hline 15 & 2491.61 & 660.00 & 394.72 & 262.8 \\
\hline 16 & 1833.09 & 390.08 & 536.49 & 312.4 \\
\hline 17 & 1688.80 & 596.60 & 277.25 & 318.4 \\
\hline 18 & 2385.33 & 660.00 & 594.66 & 309.6 \\
\hline 19 & 1425.60 & 248.67 & 417.80 & 278.0 \\
\hline 20 & 2047.01 & 660.00 & 354.51 & 309.4 \\
\hline 21 & 2670.01 & 645.09 & 615.49 & 277.2 \\
\hline 22 & 2076.65 & 651.53 & 336.09 & 331.1 \\
\hline 23 & 940.19 & 501.40 & 405.56 & 270.9 \\
\hline 24 & 1900.11 & 632.75 & 595.81 & 318.8 \\
\hline
\end{tabular}




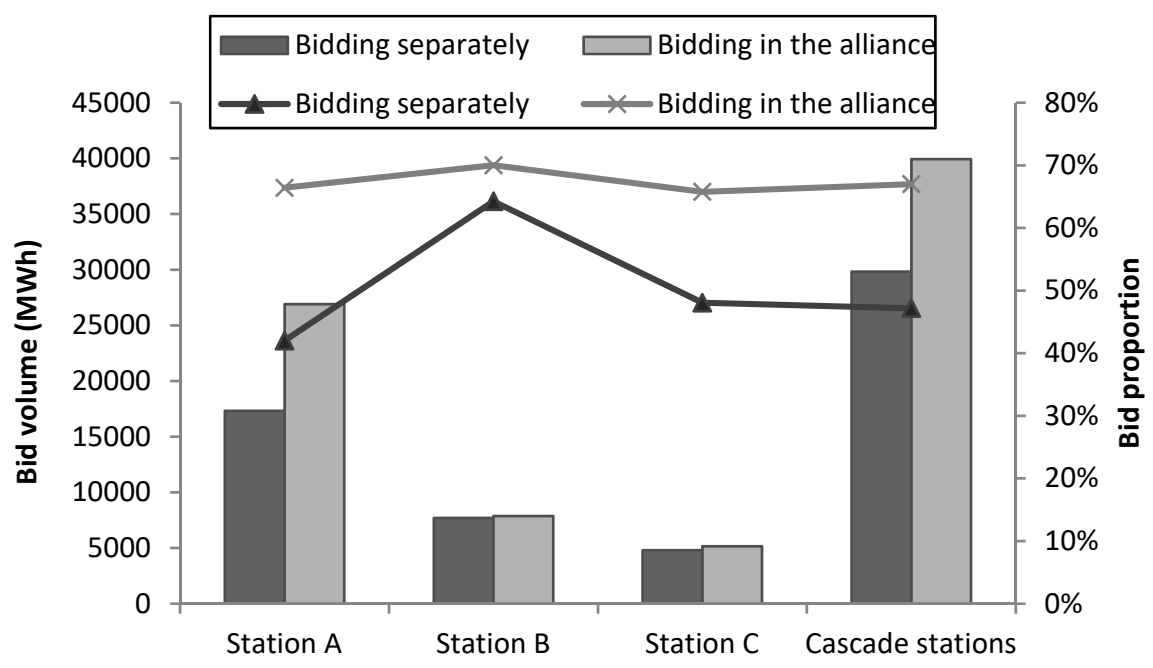

Fig. 3. Bid volume and proportion of electricity within a day

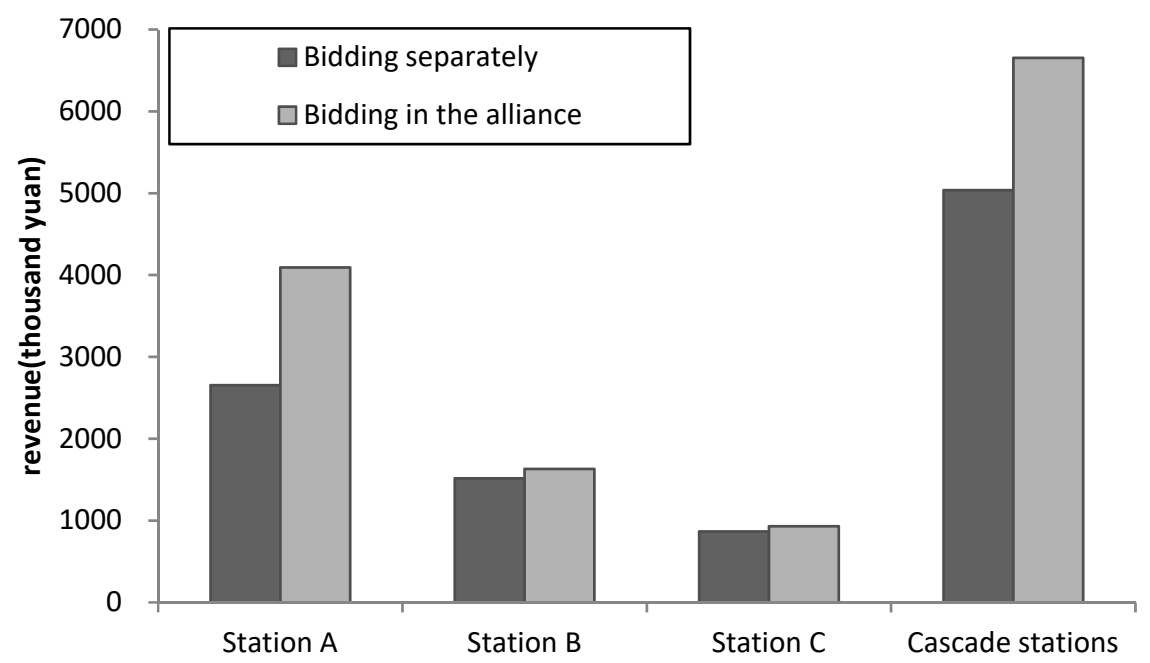

Fig. 4. Daily revenues of cascade hydropower stations

\section{Conclusions}

The hydraulic power between the multi-owner cascade power stations is related to each other, but the operation and management are relatively independent. Separate bidding is not conducive to their respective production and operation, and is not conducive to the overall effectiveness of the basin. This paper explores the combined bidding strategy of multi-owner cascade hydropower stations by establishing a bi-level optimal model of bidding game in the day-ahead market. The research shows that multi-owner cascade hydropower stations can play the joint advantage of cascade hydropower stations through combined bidding, reduce market bidding risk, and strengthen the overall market competitiveness of cascade hydropower stations. Furthermore, multi-owner cascade power stations can increase the on-grid power of each power station through the alliance bidding, and can obtain excess returns for the owners, which can be used as an effective bidding strategy for multi-owner cascade power stations in the day-ahead market.

\section{Acknowledgments}

We are very grateful for financial support from the National Key Research and Development Plan (grant nos. 2016YFC0402208 and 2018YFB0905204), Full-Time Postdoctoral Research and Development Fund of Sichuan University (2018SCU12062) and State Grid Corporation of China Headquarters' Science Project (Southwest Grid Yalong River Water-wind-PV HydroWind-Solar Complementary Optimisation Optimization Scheduling Policy Research; grant no. SGSCDK00XTJS1700047).

\section{References}

1. Liu Fang, Zhang Lizi. Bi-level Optimization Model for Medium and Long-term Scheduling and CrossPrice Area Trading Portfolio of Cascade Hydropower Stations. Proceedings of the Csee, 38(02):444-455+675 (2018). 
2. Mo Li, Ji Hongzhu, Wang Yongqiang. Symbiosis Mechanism and Its Stability of Multi-owner Cascaded Hydropower Stations. Water Resources \& Power, 31(08):230-234 (2013).

3. Liu Yue, Huang Weibin, Chen Shijun, Yang Ying. Study on Unified Collaborative Bidding and Benefit Distribution Mechanism of Multi-owner Cascade Hydropower Stations. Water Power, 44(03):77-80 (2018).

4. $\mathrm{Wu}$ Shiyong, Ma Guangwen. Theory and Methodology for Hydropower Market Competition. China Electric Power Press (2008).

5. Song Hengli. A Game Theoretical Approach to the Coalition Strategy of Cascaded Hydropower Stations. Huazhong University of Science and Technology (2013).

6. Afshar, Karim, F. S. Ghiasvand, and N. Bigdeli. Optimal Bidding Strategy of Wind Power Producers in Pay-as-Bid Power Markets. Renewable Energy (2018).

7. Cong Hao, Wang Xu, Jiang Chuangwen, et al. Coalition Game Based Optimized Operation Method for Integrated Energy Systems. Automation of Electric Power Systems, 42(14):14-22 (2018).

8. Wang J, Huang W, Ma G, et al. An improved partheno genetic algorithm for multi-objective economic dispatch in cascaded hydropower systems. International Journal of Electrical Power \& Energy Systems, 67:591-597 (2015).

9. Huang Tao, Cheng Liqin. Research on short-term optimal operation of cascade hydropower plants in electric power market. Journal of Hydroelectric Engineering, 28(3):16-21(2009).

10. Yu Weisheng, and Y. Yu. The stability of Bayesian Nash equilibrium of dynamic Cournot duopoly model with asymmetric information. Communications in Nonlinear Science \& Numerical Simulation 63 (2018). 